\title{
A GERAÇÃO DO PEIXE FRITO E A EFÍGIE DE BELÉM DO PARÁ (OU ACADEMIA RIMA COM BOEMIA, FISIONOMIA E POESIA)
}

Carla Soares PEREIRA

Kátia Regina de Souza da SILVA

Vanda do Socorro Furtado AMIN

\begin{abstract}
RESUMO
A presente pesquisa trata da Academia do Peixe Frito (APF), uma geração de poetas, artistas, jornalistas e outros intelectuais paraenses que, nas décadas de 1920 e 30, contribuíram para alavancar as letras amazônidas, fazendo literatura com dificuldade financeira e divulgando o Modernismo no Pará. Esses escritores eram boêmios e suas reuniões, informais que eram, ocorriam principalmente em bares da cidade de Belém. De cunho bibliográfico, esta investigação baseou-se nos escritos de Bolle (2000) acerca da fisionomia da cidade; de Figueiredo (2001), sobre a história literária do Pará; de Larêdo (2012) e Nunes e Costa (2016), a respeito da APF, dentre outros. Este é um texto, portanto, que compila informações sobre os locais de reunião dos membros da APF. A partir dos dados levantados, elaboramos um mapa que pontua os principais locais de encontro do grupo. Defendemos a tese de que a obra desses autores reflete múltiplas imagens da cidade e esta é refletida na vivência dos intelectuais, que, íntimos dela, perscrutam-na nas suas andanças e a enxergam na perspectiva das suas contradições.
\end{abstract}

Palavras-chave: Academia do Peixe Frito; Cidade; Literatura; Locais de encontro; Belém.

\begin{abstract}
The present research deal with Academy fried fish (APF), a generation of poets, artists, journalists and others Paraense intellectuals who, in the twenties and thirties contribute for leveraging the Amazon literatures, producing literature with financial difficult and spreading the Modernism in Pará. These writers were bohemians and their informal meetings took place mainly in pubs of Belém city, from bibliographical stamp, this investigation based itself in the Bolle's writtens (2000) about physiognomy of the Belém city, Figueiredo (2001), about literary history of the Pará, Laredo (2012) and Nunes and Costa (2016), concerning APF, among others. This research is a text which compiles information on meetings places of the APF's members. From the data collected, we elaborate a map which points the main places of group meetings. We defend the thesis of what the work of these authors reflects numerous pictures of the city and it is reflected itself in the experience of these intellectuals that, close of it, investigate it in their walks and see it in the perspective of its contradictions.
\end{abstract}

Key-words: Academy of fried fish; City; Literature; Meeting places; Belém.
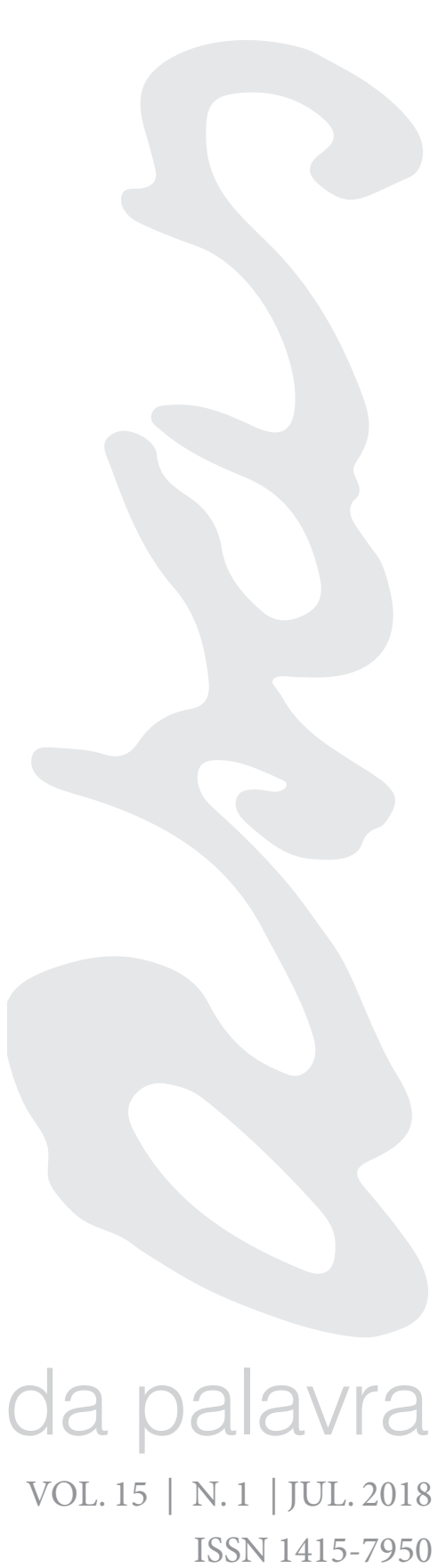


\section{PRÉVIAS}

No início, eram os "Vândalos do Apocalipse". Assim, na década de 1920, formava-se a primeira geração do grupo de intelectuais belenenses que depois seria batizado de Geração (ou Academia) do Peixe Frito. Eram jovens jornalistas, literatos, músicos que ansiavam por uma arte (sobretudo literária) diferente dos moldes tradicionais. Ali nos arredores do mercado do Ver-o-Peso, em Belém do Pará, começaram a se reunir para refletir acerca do assunto e dar os primeiros passos rumo a uma nova estética. Esses poetas-jornalistas, na sua maioria, eram jovens pobres, negros, autodidatas, provenientes da periferia de Belém, que assumiam profissões variadas para poder ganhar a vida (FIGUEIREDO, 2001; COELHO, 2003; LARÊDO, 2012; NUNES; COSTA, 2016).

Marinice Coelho (2003) realizou um estudo acerca da literatura no Pará dessa época. Neste excerto da sua pesquisa, a professora ressalta essa característica dos jovens "peixefritanos", reproduzindo palavras de um dos escritores mais atuantes da Academia: Dalcídio Jurandir, em sua primeira edição de Chove nos Campos de Cachoeira (1941): 'É Dalcídio quem cria a expressão 'geração do peixe-frito' para designar a geração de 20/30 de Belém, 'constituida de rapazes paupérrimos que faziam heroicamente literatura lutando com todas as dificuldades econômicas possiveis' [...]" (COELHO, 2003, p. 32, grifo nosso).

E era realmente assim. Publicar era (e é) uma luta para o escritor amazônida. Dalcídio viveu e relatou situações que comprovam essa luta a que ele se refere: pouco dinheiro para pagar as parcelas da máquina de escrever, sem incentivo governamental, sem dinheiro para enviar obra para participar de concurso nacional de literatura, tinha de contar com ajuda de amigos... e tinha de se esforçar muito por isso.

Bruno de Menezes também: a filha Marília Menezes, em entrevista concedida a um pesquisador, narra a situação de probreza e arrocho salarial em que viviam os pais, funcionários públicos assalariados, com grandes dificuldades para pagar aluguel, por exemplo (REIS, 2012). Além disso, a família conta que, para publicar seu primeiro livro, Bruno teve de pedir dinheiro aos amigos, numa luta a favor da propagação da cultura no Pará (WANZELER, 2016). Portanto, esses rapazes precisaram se mobilizar para soerguer as letras paraenses, principalmente as que vociferavam das classes subalternizadas.

Essa era a realidade dos acadêmicos de uma geração inovadora, rebelde, irreverente, crítica de sua sociedade e de sua época, que se autodenominou "Geração do Peixe Frito" em alusão a uma fonte de alimentação extremamente popular (porque barata) naquela época. O peixe frito era vendido nas feiras, nos mercadinhos, em postas, por preços módicos, à população. Um dos locais mais conhecidos onde o produto era vendido (e ainda o é) é o mercado do Ver-o-Peso, no centro comercial de Belém. Então, era para lá que os acadêmicos iam. E aquele se tornou o principal local de reunião do grupo que almejava revolução.

Dessa forma, percebemos que a escolha desse local como o principal para os encontros desses intelectuais paraenses refletia as condições econômicas deles, mas também espelhava sua identificação com a arraia-miúda, com os sofrimentos das gentes trabalhadoras sem voz e sem vez, com seu ideário de vanguarda. E esta inversão de paradigmas: usar o espaço da feira livre como lugar (também) de discussão e criação literária, distante dos espaços canonizados/elitizados, por si só já era uma atitude arrojada, por revelar uma mundividência crítica à frente do seu tempo.

Quanto mais estudamos e conhecemos a Academia do Peixe Frito (APF), mais percebemos que sua ligação com a cidade de Belém é umbilical. Sim, estão irremediavelmente imbrincados APF e cidade. Isso porque a APF existe na cidade,

1 Salomão Larêdo (2012, p. 38) cita, por exemplo, ativa participação dos membros da APF nos jornais Folha do Norte, $O$ Estado do Pará, A Província do Pará (segunda fase) e em revistas da época.

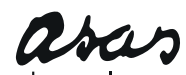

da palavra
VOL. $15 \mid$ N.1 ISSN 1415-7950 circula por ela, com suas crônicas, seus poemas, seus romances, suas prosas saborãs, seus textos publicados nos jornais... A APF existe pela cidade, para falar de suas dores, de suas contradições, de suas memórias... A APF existe para a cidade tornar-se menos omissa em relação à sua arte, despertar em termos de produção literária, acordar do marasmo pós-Belle Époque.

E quem eram esses acadêmicos do peixe-frito de que tanto falamos? Bruno de Menezes (um dos principais líderes), Abguar Bastos, De Campos Ribeiro, Jaques Flores e mais uma dezena de intelectuais. Esses "rapazes" tiveram importante participação na Revista Belém Nova, fundada por Bruno, difundida no período de 1923 a 1929 (FIGUEIREDO, 2001; COELHO, 2003). Além disso, participaram ativamente nos jornais locais, pois publicavam constantemente ${ }^{1}$, e nas mobilizações sociais, uma 
vez que consideramos que o ato de dizer também é uma forma de (re)agir, sobretudo quando se tem convicção e coerência acerca daquilo que se denuncia, como faziam os "peixefritanos" em seus textos.

E como descobrimos os seus locais de encontro? Ora, é importante dizer que alguns dos lugares foram revelados pelos filhos de Bruno de Menezes; outros, por pesquisas científicas de estudiosos da trajetória dos jovens acadêmicos e investigações afins; outros, ainda, em pistas (menções) deixadas nas obras escritas por eles.

Willi Bolle (2000) interpreta o contato do homem com a cidade e da cidade com o homem como uma relação híbrida, pois ambos exercem influência mútua e direta, como se fossem dois corpos participando simultaneamente do existir um do outro e construindo-se em história. Em uma perspectiva artístico-antropológica, percebemos que a literatura se relaciona com as experiências desse homem no contexto do lugar, daí a explicação para a presença explícita do cotidiano em textos literários.

Nesse contexto, os homens do peixe-frito estão impregnados da cidade de Belém: eles desenham-na com letras, reconstroem-na com ideias, ressignificam-na com palavras. Da mesma forma, a cidade impregna-se deles. Ela os observa, eles andam por ela, reunindo-se. Saem do Ver-o-Peso, passam pelo bairro do Jurunas, chegam a São Brás (e antigamente a cidade de Belém praticamente acabava em São Brás, no início da avenida Almirante Barroso!) e até ali eles iam, conforme observamos no mapa e nas fotos a seguir... Parece que palmilhavam a cidade na qual estavam, e que também, de modo assombrosamente poético, estava inscrita neles.

Antes de enveredar pelas próximas páginas dessa revista dedicada aos estudos de quem pesquisa a Academia do Peixe Frito, convidamos o leitor a seguir a trilha desses jovens poetas, prosadores, músicos, jornalistas pelos lugares da cidade de Belém por onde passaram².
2 Aldrin Figueiredo (2016) fez um estudo sobre o modernismo amazônico da década de 1920. Nos seus escritos, menciona os bares Leão da América e Flor de Maio como locais de encontro da Academia do Peixe Frito. No entanto, esses bares não foram assinalados no mapa por não haver uma definição de onde se localizavam.

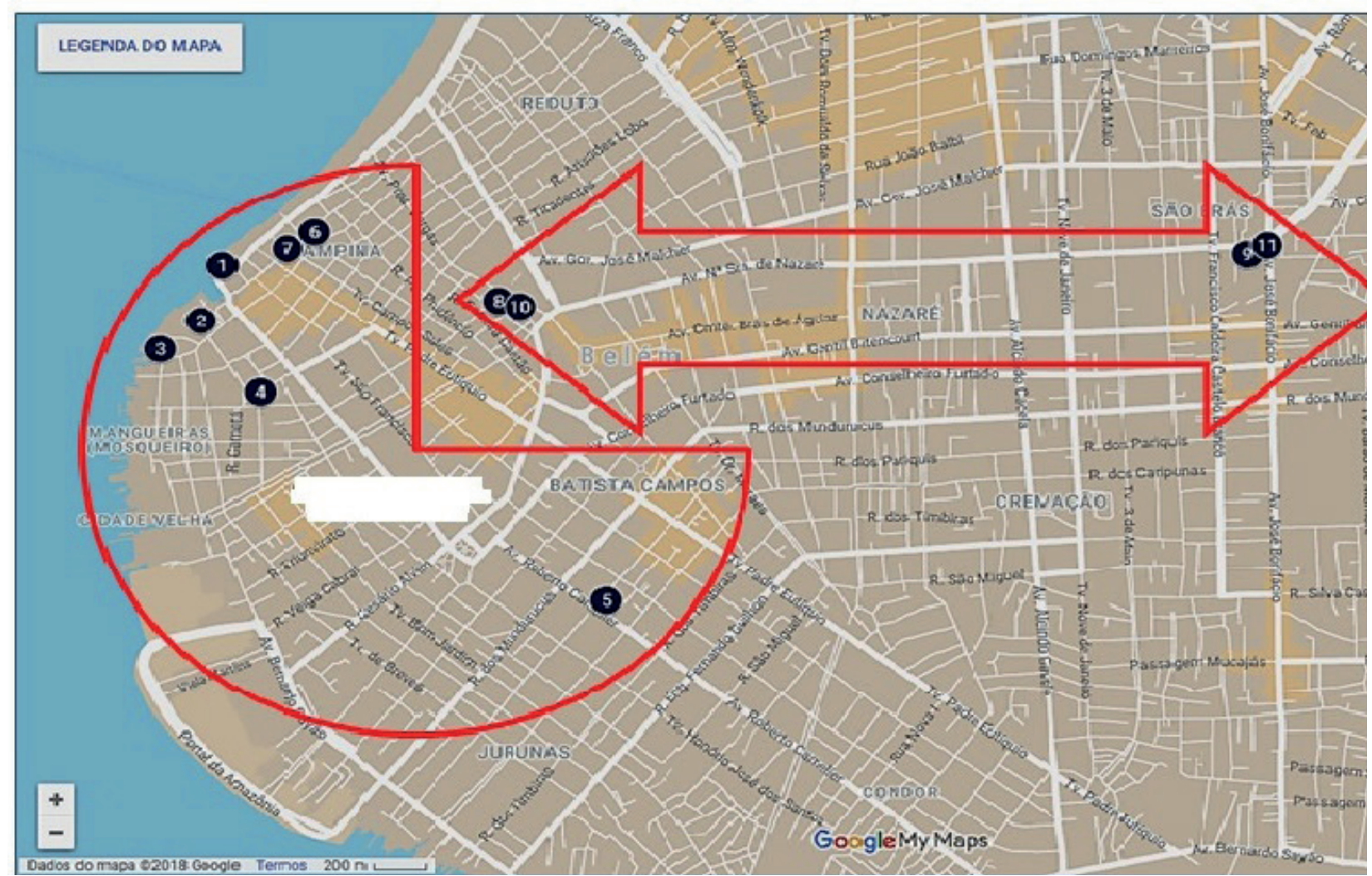

Figura 1 - Mapa dos Locais de Encontro da Academia do Peixe Frito. (Fonte: Google

Mapa. Disponível em [https://www.google.com/maps]). 


\section{O1 MERCADO DO VER-O-PESO}

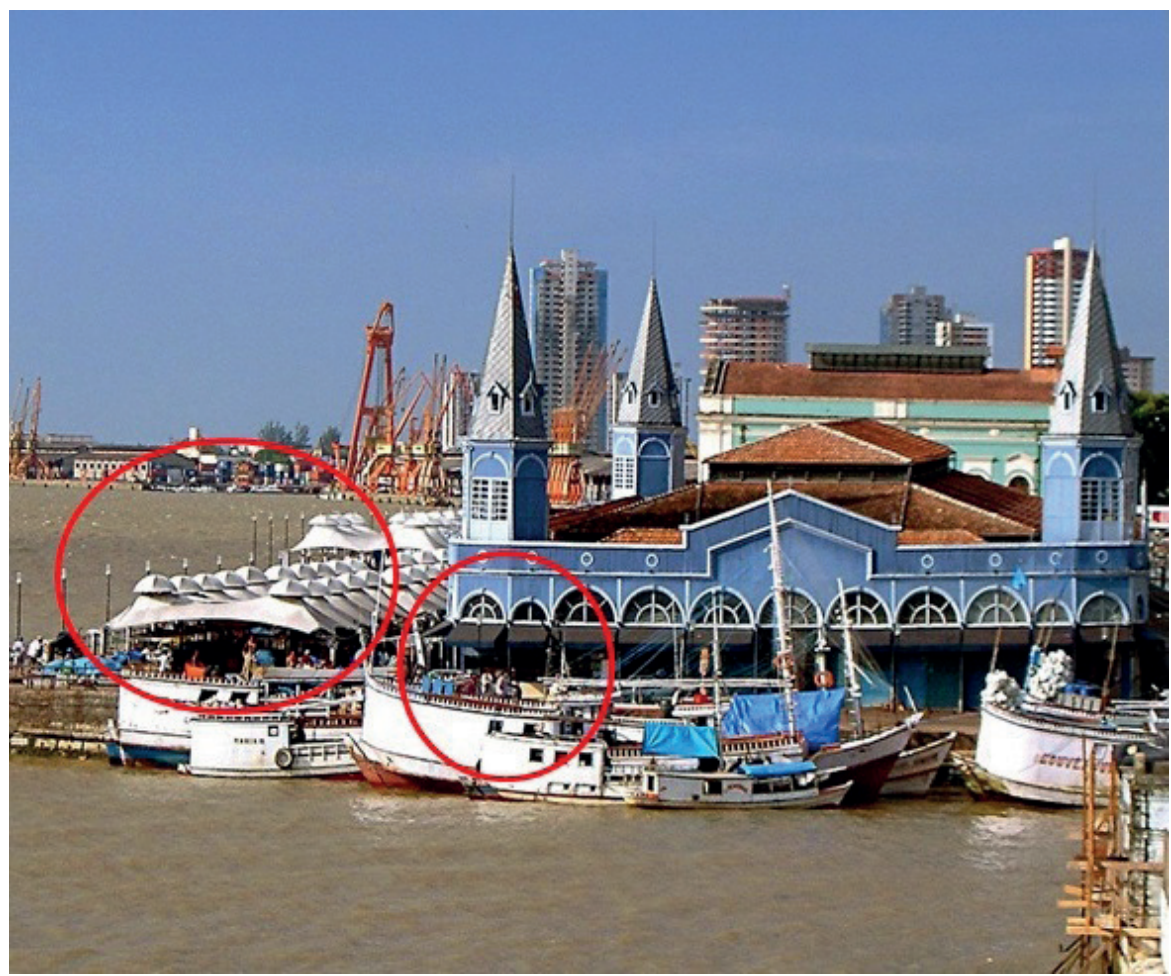

As reuniões da Academia do Peixe Frito eram informais. Os locais de encontro eram variados, mas, como já dissemos, os colóquios concentravam-se no Ver-o-Peso e nos botecos dos arredores, pois, enquanto debatiam, os membros da APF comiam peixe frito e bebiam cachaça (NUNES; COSTA, 2016). No Ver-o-Peso, seu local preferido eram as barracas onde ficavam as fritadeiras de peixe e o Bar Águia de Ouro, botequim localizado sob uma das quatro torres do Mercado de Ferro, na esquina de frente para a Avenida Portugal e para o antigo cais do porto. Esse bar era o local de guarda da imagem de São Benedito da Praia, o santo preto, muito cantado nas obras de Bruno de Menezes.

\section{ANTIGO NECROTÉRIO DE BELÉM}

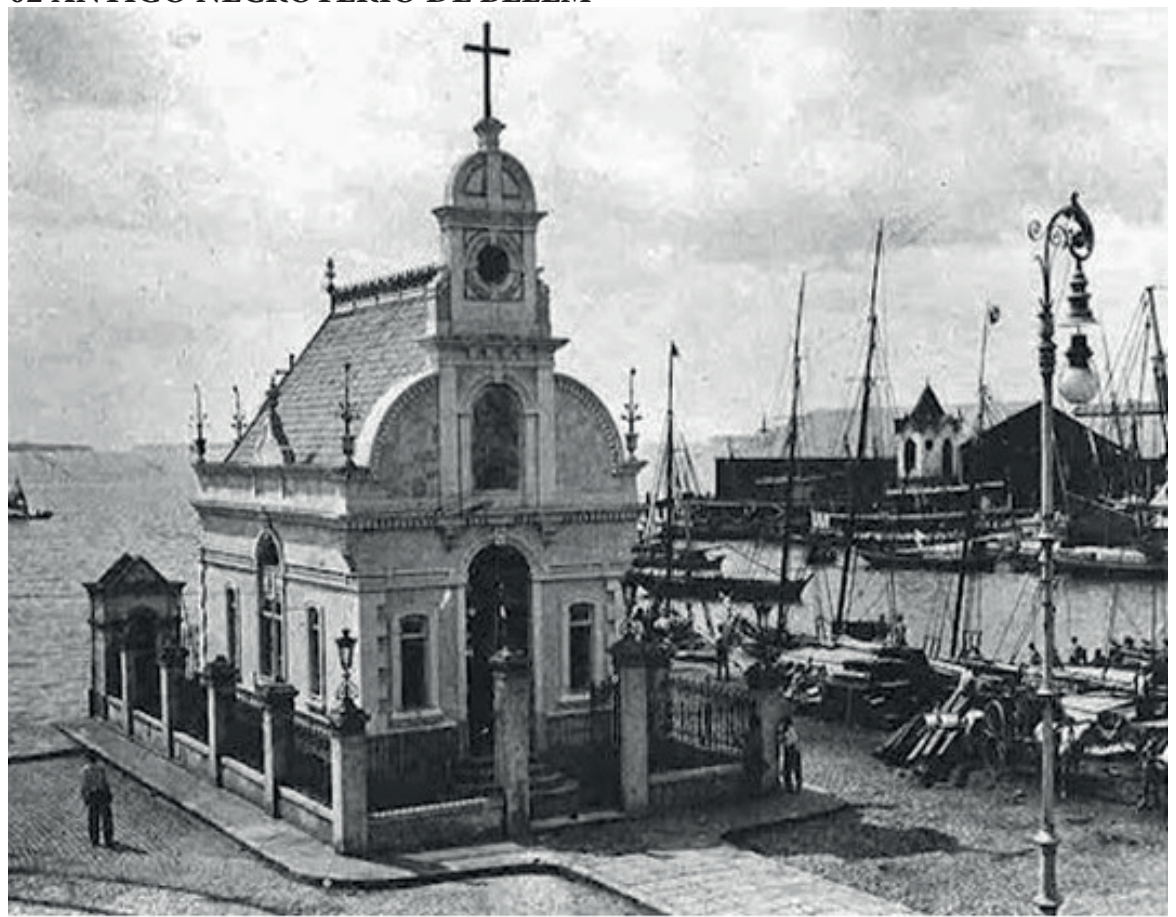

Figura 3 - Necrotério de Belém (1899). Imagem publicada originalmente no Álbum de Belém (1902). Disponível em: <https://pt-br.facebook.com/belemdopassado/photos/ a.1430888687132334.1073741828.14 30786403809229/1452102025011000 >. Acesso em: 12 jan. 2018.

\section{asas}

VOL. 15 N.1 | JUL. 2018 da palavra ISSN 1415-7950
2 - Mercado do Ver-o-Peso; das fritadeiras de peixe (à esquerda) e ocal onde ficava o Bar Águia de Ouro, so-bel\%C3\%A9m-50023/>. Acesso em: 
Ao lado do mercado do Ver-o-Peso, próximo à área do Porto do Açaí, destaca-se o cenário do antigo necrotério, construído em 1899, enquanto Antônio Lemos era o prefeito (intendente) de Belém. A localização do necrotério próximo ao cais, de frente para o rio, era estratégica e fazia parte da política de assepsia da cidade moderna (SARGES, 2002; 2010). O necrotério não era um lugar propriamente de reunião da APF, mas, na ilharga ${ }^{3}$ do Veropa, marcou a obra Belém do Grão-Pará, de Dalcídio Jurandir. Nesse romance, assim que a personagem Alfredo desembarca em Belém, uma de suas primeiras experiências narradas é sobre um morto na pedra do necrotério. Logo, esse espaço não passou incólume à APF.

\section{GARAGEM DO CLUBE DO REMO}

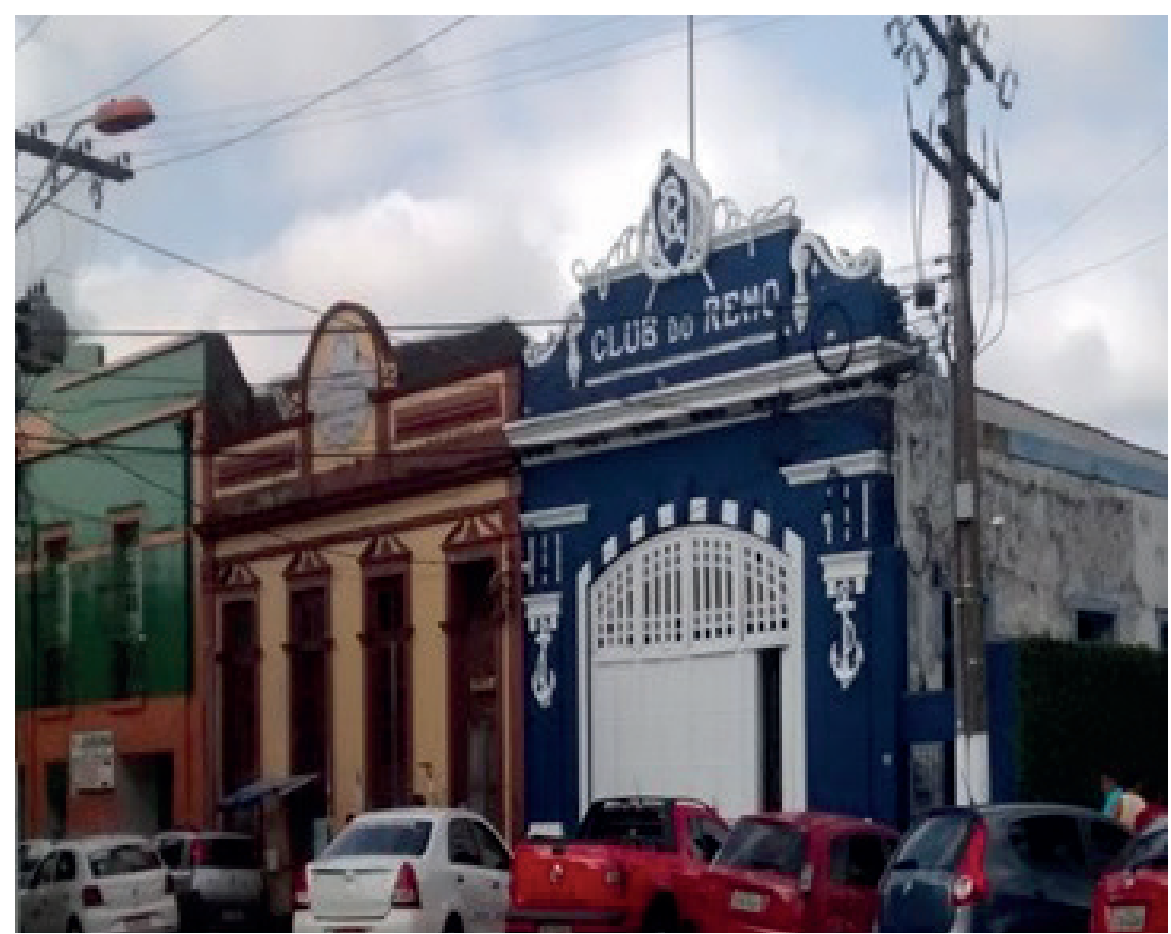

Esse espaço localiza-se na rua Siqueira Mendes, a histórica primeira rua de Belém. Também nas imediações do Ver-o-Peso, na Cidade Velha, era um dos locais de encontro do grupo. Nos fundos dessa Garagem funcionava um bar, de frente para o rio, bastante frequentado pelos escritores da APF.

\section{CASA DO BRUNO DE MENEZES (RUA JOÃO DIOGO)}

A casa da rua João Diogo, n. 26, no bairro da Campina, onde Bruno de Menezes morou com a família, depois de casado, também foi um dos pontos de encontro do grupo. Os relatos de memória dessa época são dos filhos de Bruno de Menezes, sobretudo de Marília Menezes, segundo a qual os "moços" do peixe-frito reuniam-se naquela casa.

\section{BAIRRO DO JURUNAS}

Bruno de Menezes, na juventude, morou no Jurunas, bairro antigo, populoso e pobre de Belém, formado em sua maioria por descendentes de nordestinos, africanos e indígenas (NUNES; COSTA, 2016). Então, provavelmente, reunia-se com a APF na sua própria casa, antes de mudar-se para a Campina, ou na casa de familiares e amigos, mas não há registros consistentes sobre isso. Há informações colhidas por
Figura 4 - Garagem do Clube do Remo. Fonte: Arquivo pessoal das autoras (2017).
3 Ilharga é uma expressão empregada por muitos paraenses que significa "lado", "lateral", "junto de". Veropa é uma forma popular e carinhosa de se referir ao mercado do Ver-o-Peso. 
pesquisadores, com moradores e familiares no próprio Jurunas, sobre a vida do poeta, de que ele era muito conhecido nesse bairro, pois tinha participação ativa na comunidade, inclusive fundando cooperativa de trabalho (WANZELER, 2016). Também, em seus poemas, sobretudo naqueles constantes na obra Batuque, de 1931, Bruno revela sua profunda identificação com a comunidade negra, por meio das práticas culturais que aludem à negritude.

\section{BAR CARIOCA E BAR FLOR DE BELÉM}

Figura 5 - Largo das Mercês e entorno. A seta aponta para o local onde se situavam os bares Carioca e Flor de Belém. Imagem disponível em: <http:// www.skyscrapercity.com/show thread.php? $=59575475>$. Acesso em: 28 dez. 2017.

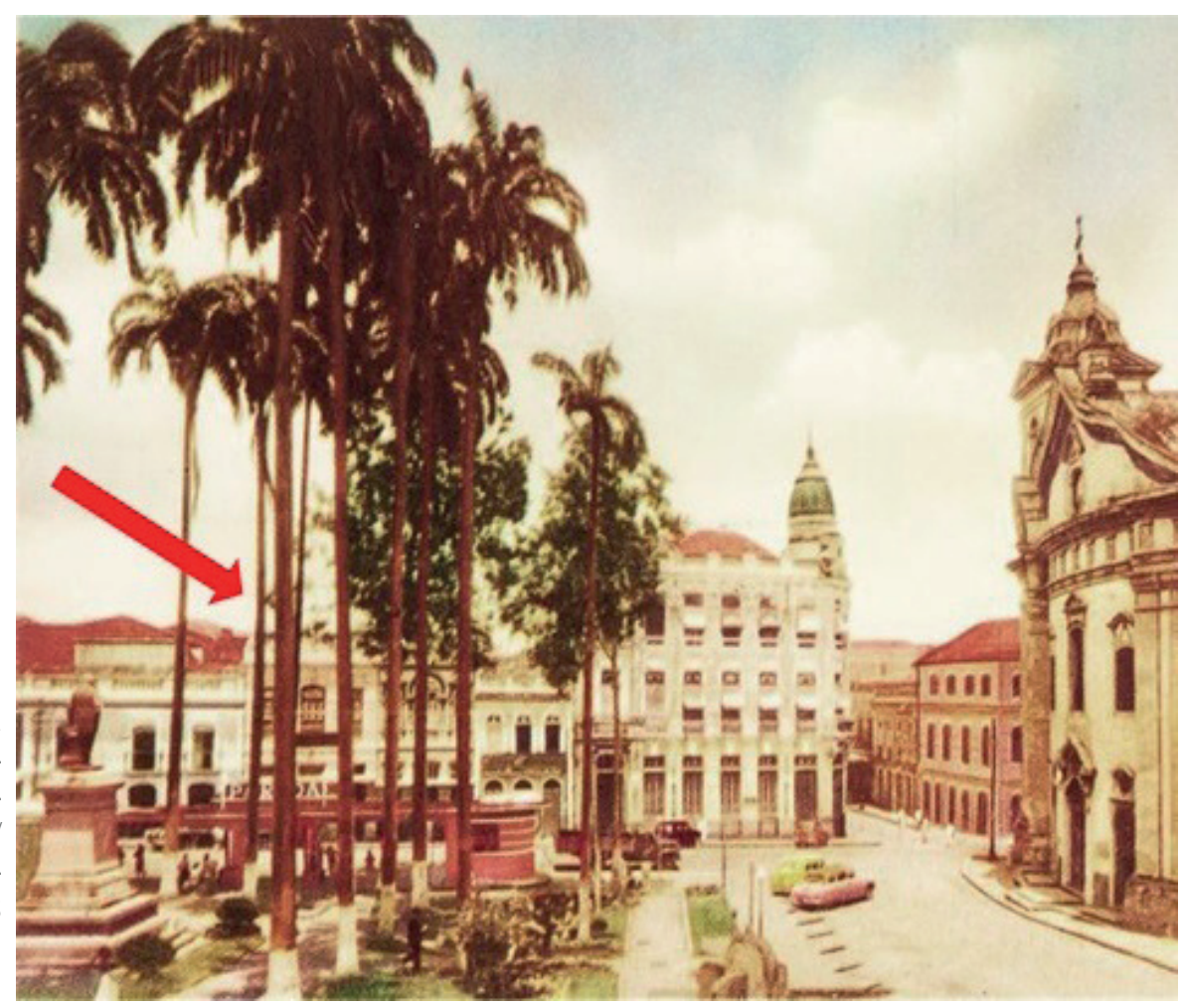

Esses bares localizavam-se no Largo das Mercês, na travessa Frutuoso Guimarães, no bairro da Campina, não muito distantes do Ver-o-Peso, em Belém. Naquela época, essa já era uma área comercial. O Carioca e o Flor de Belém ficavam praticamente lado a lado, pois o espaço era um complexo de bares muito frequentado por boêmios (LARÊDO, 2012).

\section{BAR BARBINHA}

Segundo Larêdo (2012), José Haroldo Menezes, filho de Bruno, relata que a APF também se reunia em um bar denominado Barbinha, cujo dono era português. Esse bar ficava na Travessa Campos Sales, esquina com a 15 de Novembro, no centro comercial de Belém.

\section{CITY CLUB}

4 A obra a que nos reportamos é Gos-

O City Club ficava próximo à Praça da República, no prédio Cedro, onde tosa Belém de Outrora.

funcionava na época a sede do Clube Monte Líbano (e, hoje, as Lojas Americanas), ao lado do Cinema Olímpia. O próprio De Campos Ribeiro, um jornalista membro da Academia, em uma de suas crônicas ${ }^{4}$, menciona parte dessa história, recontada por Correa (2008) e Larêdo (2012): as noites dos "rapazes" do peixe-frito começavam no

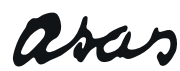

da palavra
VOL. 15 | N.1 | JUL. 2018 ISSN 1415-7950
Bar Paraense e no Bar Pilsen, depois continuavam geralmente no City Club e, de lá, o grupo rumava para o bar Kean. 

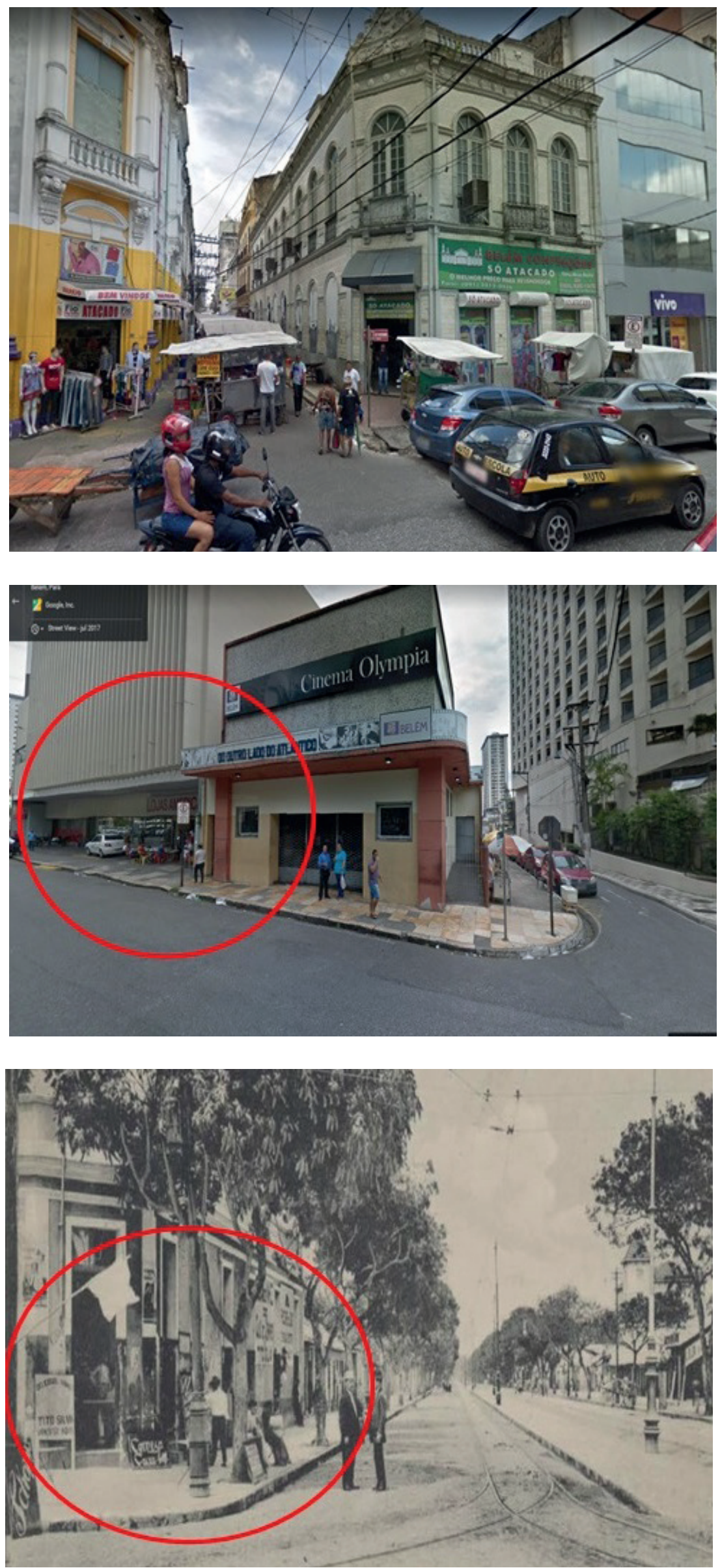

Figura 6 - Espaço atual onde se localizava o Bar Barbinha. Esquina da rua 15 de Novembro com a Campos Sales, (lado direito) onde hoje está a loja Belém Confecções. Imagem do Google Mapas disponível em: $<$ https://www.google.com.br/maps/@-1.451573,-48.5015386,3a,75y,1 $45.2 \mathrm{~h}, 93.82 \mathrm{t} / \mathrm{data}=! 3 \mathrm{~m} 6$ ! $1 \mathrm{e} 1 ! 3 \mathrm{~m} 4$ ! 1 s OR-9 NbHplFQDLZ1xpyLdSA!2e0!7i13312!8i6656>. Acesso em: 20 jan. 2018.

Figura 7 - Espaço atual onde se localizava o City Club. Imagem capturada do Google Mapas, disponível em: <https://www.google.com.br/maps/@1.4537004>. Acesso em: 12 jan. 2018.

Figura 8 - Localização do complexo de bares da rua Independência. A imagem reporta à rua Independência (atual Magalhães Barata), esquina com a José Bonifácio, no bairro de São Brás, em Belém do Pará. Pela Independência, os bares Pilsen e Paraense; pela José Bonifácio, o Bar Kean, em destaque na figura. Disponível em: <http:// fragmentosdebelem.tumblr.com/ post/41698916860>. Acesso em: 20 jan. 2018. 


\section{BAR PARAENSE E BAR PILSEN}

Esses dois bares eram bem próximos um do outro e ficavam na avenida Independência (atual Magalhães Barata), próximo à avenida José Bonifácio. O Pilsen e o Paraense faziam parte de um complexo de uma cervejaria muito famosa naquela rua. Esse complexo tomava todo um quarteirão (da Independência até atrás da próxima avendida, a Gentil Bitencourt). Nele havia cinema, bares, como um espaço bem aprazível para a boemia belenense de décadas atrás (CORREA, 2008). Larêdo (2012) cita o espaço como ponto de encontro da Geração do Peixe Frito.

\section{CAFÉ CHIC E CAFÉ DA PAZ}

Figura 9 - Terraço do Grande Hotel. Imagem disponível em: $<$ https://www.pinterest.co.uk/ $\operatorname{pin} / 474566879464118314 />$. Acesso em: 20 dez. 2017.

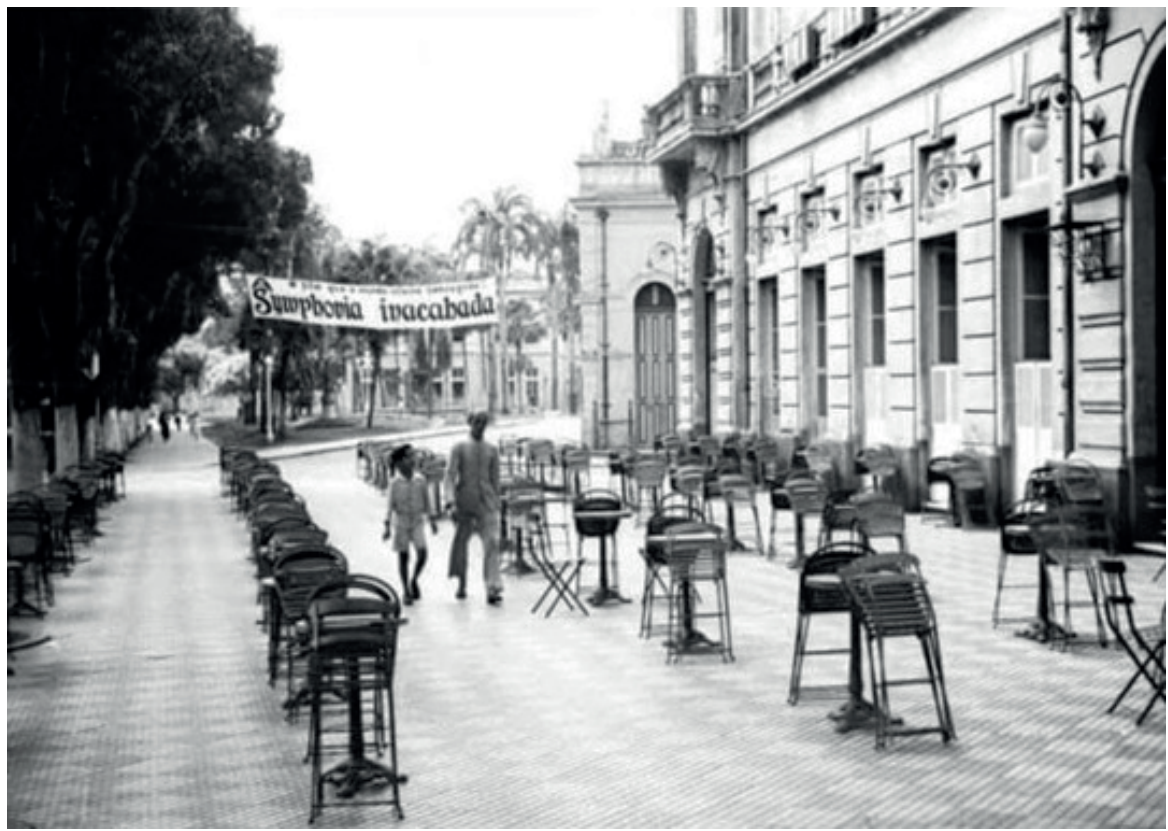

Apesar de não ser um local com o qual se identificavam socialmente, os moços da APF também frequentavam as rodas sociais de importantes intelectuais da época. Portanto, quando eram convidados, ou mesmo quando desejavam, abancavam-se no Café Chic e no Café da Paz, no terraço do Grande Hotel (que depois foi o Hilton Hotel e atualmente é o Hotel Princesa Louçã), em frente à Praça da República. Esse era um espaço prestigiado, frequentado pela elite paraense, mas que também testemunhou reuniões dos rapazes do peixe-frito. Um dos pesquisadores que registrou a passagem da APF nesse local foi Larêdo (2012).

\section{BAR KEAN}

Outro núcleo boêmio na primeira metade do século XX, segundo Corrêa (2008), eram as proximidades do mercado de São Brás. Todo o arredor ali era festivo, cheio de bares frequentados por vários grupos de intelectuais da época. O Bar Kean ficava no Largo de São Brás, em frente ao mercado, onde também compareciam os membros da APF. Próximo dele, havia outros dois bares íntimos dos rapazes da APF, o Paraense e o Pilsen. De Campos Ribeiro descreve o Kean como parada obrigatória para o fim das noitadas boêmias. Para lá convergiam os acadêmicos do peixe-frito, no intuito de terminar a noite junto do amigo Tó Teixeira (também da APF) e de outros músicos, cantores, compositores que animavam os boêmios com músicas e conversas. Dali só seguiam para casa ao raiar do sol. 


\section{REFERÊNCIAS}

BOLLE, Willi. Fisiognomia da metrópole moderna: representação da história em Walter Benjamin. 2. ed. São Paulo: Edusp, 2000.

COELHO, Marinilce Oliveira. Memórias literárias de Belém do Pará: o Grupo dos Novos, 1946-1952. Campinas, SP, 2003.

CORREA, Ângela Tereza de Oliveira. A vida noturna em Belém: a boêmia poética. Poder, Violência e Exclusão. ANPUH/SP, USP. São Paulo, 2008.

FIGUEIREDO, Aldrin Moura de. Eternos modernos: uma história social da arte e da literatura na Amazônia, 1908-1929. Tese (Doutorado em História Social). Instituto de Filosofia e Ciências Humanas. Unicamp, Campinas, 2001.

FIGUEIREDO, Aldrin Moura de. De pinceis e letras: Os manifestos literários e visuais no modernismo amazônico na Década de 1920. Revista Territórios \& Fronteiras, Cuiabá, v. 9, n. 2, jul.-dez. 2016.

JURANDIR, Dalcídio. Belém do Grão-Pará. Belém: EDUFPA; Rio de Janeiro: Casa de Rui Barbosa, 2004.

JURANDIR, Dalcídio. Chove nos campos de Cachoeira. 1. ed. Rio de Janeiro: Vecchi Editor, 1941.

LARÊDO, Salomão. Geração peixe frito ou Academia do peixe Frito. Belém: 2012.

MENEZES, Bruno de. Batuque. 8. ed. Belém: GTR, 2015.

NUNES, Paulo; COSTA, Vânia. Academia do Peixe Frito: diálogos e intersecções entre Literatura, jornalismo e Ciências Sociais na Amazônia do século XX. $40^{\circ}$ Encontro Anual da Anpocs. Anais..., Caxambu, out. 2016. Disponível em: $<$ http://www.anpocs.com/index. $\mathrm{php} /$ papers-40-encontro/st-10/st02-8/10533-academia-do-peixe-frito-dialogos-e-interseccoes-entre-literatura-jornalismo-e-ciencias-sociais-na-amazonia-do-seculo-xx/file>. Acesso em: 10 jan. 2018.

REIS, Marcos Valério Lima. Entre poéticas e batuques: trajeitórias de Bruno de Menezes. 2012. 157f. Dissertação (Mestrado em Comuicação, Linguagens e Cultura), PPGCLC, Universidade da Amazônia, Belém, 2012.

RIBEIRO, De Campos. Gostosa Belém de Outrora. 2005, p. 129.

SARGES, Maria de Nazaré. Memórias do Velho Intendente. Belém: Paka-Tatu, 2002 (Coleção Açaí).

SARGES, Maria de Nazaré. Belém: Riquezas Produzindo a Belle Époque (1870-1912). 3. ed. Belém: Paka-Tatu, 2010.

WANZELER, Rodrigo de Souza. Bruno de Menezes: fragmentos de memórias (des)construindo histórias de vida de um literato-etnógrafo. In: XIII Encontro Nacional de História Oral. Universidade Federal do Rio Grande do Sul, Porto Alegre, maio 2016. Disponível em: $<$ http://www.encontro2016.historiaoral.org.br/resources/anais/13/1461872632_ARQUIVO_ ARTIGOHISTORIAORAL-POA.pdf>. Acesso em: 02 fev. 2018. 


\section{Recebido em 02 Mai 2018 Aprovado em 12 Jul 2018}

Carla Soares PEREIRA

Mestre e doutoranda do Programa de Pós-Graduação em Comunicação, Linguagens e Cultura, Universidade da Amazônia (UNAMA/Ser Educacional); Bolsista/Taxa do Programa de Suporte à Pós-Graduação de Instituições de Ensino Particulares (PROSUP) da Coordenação de Aperfeiçoamento de Pessoal de Nivel Superior (CAPES). Membro do Grupo de Pesquisa Academia do Peixe Frito/UNAMA. Professora de Língua Portuguesa do I Comando de Aeronáutica/Escola Tenente Rêgo Barros, Belém, Brasil.E-mail: carlasp21@hotmail.com

Kátia Regina de Souza da SILVA

Especialista em Lingua Portuguesa: Uma abordagem textual e em Relação Étnico-racial para o Ensino Fundamental, pela Universidade Federal do Pará (UFPA); graduada em Letras/Lingua Portuguesa, pela Universidade da Amazônia (UNAMA); membro do Grupo de Pesquisa Academia do Peixe Frito/UNAMA.E-mail: katiaregina.silva@unama.br

Vanda do Socorro Furtado AMIN

Mestre e doutoranda pelo Programa de Pós-Graduação em Comunicação, Linguagens e Cultura da Universidade da Amazônia (UNAMA/Ser Educacional). Bolsista/Taxa do Programa de Suporte à Pós-Graduação de Instituições de Ensino Particulares (PROSUP) da Coordenação de Aperfeiçoamento de Pessoal de Nivel Superior (CAPES). Bacharel em Direito. Professora de Lingua Portuguesa do I Comando da Aeronáutica/Escola Tenente Rêgo Barros, Belém, Brasil.E-mail: vanda_amin@hotmail.com 